\title{
Isoenzyme type 1 of 5 alpha-reductase is abundantly transcribed in normal human genital skin fibroblasts and may play an important role in masculinization of 5alpha-reductase type 2 deficient males
}

\author{
Susanne Thiele, Ute Hoppe, Paul-Martin Holterhus and Olaf Hiort \\ Division of Pediatric Endocrinology and Diabetes, Department of Pediatrics, University of Lübeck, Lübeck, Germany \\ (Correspondence should be addressed to O Hiort; Email: hiort@paedia.ukl.mu-luebeck.de)
}

\begin{abstract}
Objective: 5alpha-reductase enzymes reduce testosterone (T) to the most potent androgen dihydrotestosterone (DHT). Two isoenzymes are known to day. While the type 2-enzyme (5RII) is predominantly expressed in male genital tissues and mutations are known to cause a severe virilization disorder in genetic males, the role of the type 1-enzyme (5RI) in normal male androgen physiology is unclear. We investigated whether 5RI is transcribed in normal male genital skin fibroblasts (GSFs) and if the transcription is regulated by age or by androgens themselves.

Methods: GSF from 14 normally virilized males of different ages, ranging from 8 months to 72 years, obtained at circumcision were cultured. Total RNA was isolated after incubation for $48 \mathrm{~h}$ with $100 \mathrm{nM}$ T or without androgens. Each sample was amplified in triplicate by real-time PCR with porphobilinogen desaminase as a housekeeping gene used for semiquantification. Selected cultures were analyzed after incubation with 10 and $100 \mathrm{nM}$ T and 1 and $100 \mathrm{nM}$ DHT for 24, 48 and $120 \mathrm{~h}$. Results: 5RI was transcribed in all investigated samples with a 4.5-fold variability in the mRNA concentration of different individuals. However, neither age-related regulation nor significant influence of $\mathrm{T}$ or DHT on the transcription rate was discovered.

Conclusion: Since 5RI is abundantly transcribed in GSFs, we hypothesize that this isoenzyme may play important roles in the androgen physiology of normally virilized males and may contribute to masculinization in 5RII-deficient males at the time of puberty.
\end{abstract}

European Journal of Endocrinology 152 875-880

\section{Introduction}

Conversion of testosterone (T) to dihydrotestosterone (DHT), the most potent known androgen in humans, is performed by two isoenzymes of 5alpha-reductase. 5alpha-reductase type 2 (5RII) is predominantly expressed in male genital tissues and is indispensable for normal virilization of the external male genitalia during embryonic life. Mutations in the corresponding gene, SRD5A2, lead to a severe virilization deficit in genetic males termed 5alpha-reductase type 2 deficiency $(1-4)$.

In contrast, 5RI is not expressed in human genital skin fibroblasts (GSFs) during embryogenesis, and natural mutations in the corresponding gene, SRD5A1, have not been described in human disorders of somatosexual differentiation (5). Therefore it was concluded that 5RI does not play an important role in early male sexual development. However, there is distinct evidence for the possible importance of 5RI for postnatal sexual differentiation: individuals with mutations in SRD5A2 and resulting 5alpha-reductase type 2 deficiency show regular, clear, but unexplained signs of virilization during puberty even in cases of homozygous disruptive mutations (6). This can occur to such an extent that affected individuals change their sex of rearing from female to male $(1,3,7,8)$. Furthermore, these individuals can show normal DHT-concentrations (1) and normal T/DHT-ratios $(4,9)$ in serum. Additionally, testosterone treatment can lead to an increase of DHT-levels up to normal values $(1,10)$. The conversion of $\mathrm{T}$ to DHT with following virilization could be catalysed by 5RI in these individuals. On the basis of these observations, we hypothesized that DHT-synthesis in GSFs is possible due to the expression of both isoenzymes. Evidence for this is given by earlier biochemical studies in GSFs. These have demonstrated the enzymatic activity of 5RII with a $\mathrm{pH}$ optimum at 
5.5, but also an additional broad shoulder of activity extending over a more alkaline range, reflecting the activity of 5RI $(2,5)$.

We focused our study on the transcription pattern of 5RI in GSFs, which represent a well established stromal-derived cell culture model for male sexual differentiation research. Using semiquantitative real-time-PCR, we investigated whether this isoenzyme is transcribed in all age groups in GSF-cultures of normal virilized males, and if there is an age-related transcription pattern. Furthermore we wanted to find out if the RNAexpression of $5 \mathrm{RI}$ is regulated by its substrate $\mathrm{T}$ or its product DHT.

\section{Material and methods}

\section{Cell cultures}

Foreskins from 14 normally virilized males of different ages ranging from 8 months to 72 years were obtained at circumcision, dissected mechanically, and incubated in medium (DMEM-F12, Gibco, 5\% CO2, 10\% charcoalstripped fetal calf serum, streptomycine and penicillin) at $37^{\circ} \mathrm{C}$ to culture GSFs, and subsequently stored in liquid nitrogen. For further analysis, cells of the second passage were used. After thawing, GSFs were first grown to approximately $80 \%$ confluence and then pre-incubated in medium without androgens for $48 \mathrm{~h}$. Cells were afterwards incubated in medium containing either $100 \mathrm{nM} \mathrm{T}$ or no hormone for $48 \mathrm{~h}$. Additional cultures of the fourth passage from 8 month, 12 year and 42 year old males were incubated with $10 \mathrm{nM}$ and $100 \mathrm{nM} \mathrm{T}$, and $1 \mathrm{nM}$ and $100 \mathrm{nM}$ DHT for 24,48 and $120 \mathrm{~h}$ respectively. To create standard curves for real time PCR, blood of a normal virilized adult male was obtained with the PAXgene Blood RNA Kit (PreAnalytiX, Switzerland).

\section{RNA analysis and reverse transcription}

Total RNA from GSFs and blood was isolated using Rneasy columns according to the manufacturer's instructions (Qiagen, Hilden, Germany). RNA was quantified photometrically by measuring the absorbency at $260 \mathrm{~nm}$ in a DNA/RNA calculator (Pharmacia, Freiburg, Germany). To determine the quality and integrety of RNA, $5 \mu$ l aliquots were electrophoresed on formaldehyde-denaturing $1 \%$ agarose gels.

Reverse transcription was achieved by random primer (Invitrogen, Mannheim, Germany). $1 \mu \mathrm{g}$ of whole RNA from each GSF sample was used. RNA, $20 \mathrm{pmol}$ of random primer and DEPC-H2O were added to a final volume of $10 \mu \mathrm{l}$. Mixtures were incubated at $70^{\circ} \mathrm{C}$ for $5 \mathrm{~min}$. Then $1 \mathrm{x}$ first-strand buffer, $1 \mathrm{mM}$ dNTPs, $10 \mathrm{mM}$ DTT and $10 \mathrm{U}$ Rnase inhibitor (Boehringer-Mannheim, Mannheim, Germany) were added to a final volume of $20 \mu \mathrm{l}$. Reverse transcription was performed with $40 \mathrm{U}$ Superscript II RT (Gibco BRL,
Eggenstein-Leopoldshafen, Germany) at $37^{\circ} \mathrm{C}$ for $1 \mathrm{~h}$ using a thermocycler (PTC 200 DNA-engine, Biozym, Germany).

\section{Real-time RT-PCR and melting curve analysis}

SYBR Green (LightCycler-DNA Master SYBR Green I, Roche, Mannheim, Germany) was used as fluorescent signal in Real-Time PCR employing the LightCycler (Light-Cycler System, Software 3.0, Roche, Mannheim, Germany). For standardisation we used porphobilinogen desaminase (PBGD) as a control.

To synthesize standard curves for target and standard, we performed a dilution from 1:1 to 1:10000 from the blood-RNA. The PCR-solution contained $10 \mu \mathrm{l}$ of cDNA in different dilutions, $20 \mathrm{pmol}$ of 5RI sense primer (5'-GGT-TTT-GGC-TTG-TGG-TTA-ACA$\left.3^{\prime}\right)$ and $20 \mathrm{pmol}$ of 5RI antisense primer (5'-CTC-TTCAAA-TTT-CCG-GAG-GTA -C- $3^{\prime}$ ), 20 pmol of PBGD sense primer (5'-AGA-GTG-ATT-CGC-GTG-GGT-ACC$\left.3^{\prime}\right)$ and of PBGD antisense primer (5'-GGC-TCC-GATGGT-GAA-GCC-3') (TIB MOLBIOL, Berlin, Germany); $4 \mathrm{mM} \mathrm{MgCl} 2$ and $2 \mu \mathrm{l}$ FastStart DNA Master SYBR Green I. Mixtures were produced according to the manufacturers instructions (Roche, Mannheim, Germany). Cycling conditions were: $10 \mathrm{~min}$ denaturation at $95^{\circ} \mathrm{C}$ to activate the polymerase, followed by amplification cycles: $15 \mathrm{~s}$ denaturation at $95^{\circ} \mathrm{C}, 10 \mathrm{~s}$ primer annealing at $65^{\circ} \mathrm{C}, 30 \mathrm{~s}$ primer extension at $72^{\circ} \mathrm{C}$ and $5 \mathrm{~s}$ measuring of fluorescence at $81{ }^{\circ} \mathrm{C}$ for 40 cycles. Each dilution was amplified three times in PCR, calculated by Light-Cycler Software 3.0 (Roche, Mannheim, Germany) and subsequently shown on a logarithmic scale as standard curves.

RNA obtained from GSFs was amplified under the same conditions. To load the standard curves, we used two calibrators for each PCR. All samples were included in duplicate and each experiment was repeated three times (11). Due to the reliable results, cultures which were incubated with different concentrations of T and DHT were amplified only once.

To confirm the PCR product identity, each PCR was followed by a melting curve-analysis. After the final cycle, the products were denaturated at $95^{\circ} \mathrm{C}$, annnealed at $70^{\circ} \mathrm{C}$, and slowly heated from $70^{\circ} \mathrm{C}$ to $95^{\circ} \mathrm{C}$. During the slow heating process, fluorescence was measured. The fluorescence of the SYBR Green dye bound to the double-stranded amplicon dropped sharply as the fragment degraded. Specific identity of the PCR-products was confirmed by direct sequencing (Seqlab, Mannheim, Germany).

\section{Results}

5RI mRNA as well as PBGD was successfully detected in all samples by Real-Time PCR. The standard deviation did not show significant variations between the 
different PCRs. Furthermore, we could show a constant transcription level of PBGD under androgen incubation compared with hormone-free conditions by evaluation of the crossing points (results not shown). We confirmed the specific identity of both PCR products by direct sequencing, revealing the published sequence of 5RI and PBGD (http://www.ncbi.nlm.nih.go).

The 5RI-transcript was found in all different age groups. We measured the highest concentrations of mRNA in cultures of the 42 and 51 year old males, but there were no significant differences in the mRNA-concentrations between children and adults. Additionally, no obvious association with age was discovered. However, we found an up to 4.5-fold variability in the 5RI mRNA-concentration of different individuals (see Fig. 1).

We investigated the identical 4 cell lines from 2, 7 , 42 and 51 year old males in whom Hellwinkel et al. had previously reported an age-related down-regulation of the mRNA-concentration of 5RII (12). Due to different methods being used by Hellwinkel et al. and due to low sample number, a statistical analysis comparing the previous and the present results was not possible. However, on the basis of the obtained results, it may be postulated that the relation of transcription of type 1 to type 2 increases with age.

When values of cells incubated with $\mathrm{T}$ and without androgens were depicted, no characteristic difference was found (see Fig. 2). Moreover, most samples of prepubertal males showed a relatively similar mRNA-concentration. In contrast, cell cultures of the 42,48 and 51 year old males showed a more pronounced variability. Also in these samples, no significant differences between hormone treated and untreated cells were present.

These findings were reproducible in further experiments employing either a shortened or a prolonged $\mathrm{T}$ exposure at concentrations of $10 \mathrm{nM}$ and $100 \mathrm{nM}$ using pre-pubertal (8 month old), juvenile (12 years old) and post-pubertal (42 years old) GSF and incubation times of 24,48 and $120 \mathrm{~h}$ respectively. In an attempt to analyze the effect of the more potent androgen DHT on 5RI transcription, we exposed the cell lines to $1 \mathrm{nM}$ and $100 \mathrm{nM}$ of DHT for increasing periods of time. Again, no change in transcript levels was observed, no matter which DHT concentration was used and no matter how long the incubation time was.

\section{Discussion}

We found the mRNA of 5alpha-reductase type 1 in all investigated GSF cultures. GSFs represent a well established stromal-derived cell-culture model for male sexual differentiation research. They originate from the external genitalia - the most obvious androgen target tissue during male sexual differentiation - and they express the androgen receptor as the mediator of androgen action (13-17). Furthermore, these cells have been used to demonstrate the activity of both 5alpha-reductases as well as the decreased 5RIIactivity in patients affected by 5RII deficiency for diagnostic purposes $(1,5)$.

Our results are in accordance with further studies investigating the transcription of 5RI in other human genital tissues. 5RI is transcribed in different androgen-dependent organs like the epididymis (18), the testis (19) and the prostate $(20,21)$. The localisation of 5RI in the cell nucleus of human prostate cells (22) and the close spatial relationship to the androgen receptor in prostate, epididymidis and testis reported by Aumüller et al., also suggest a functional connection between this isoenzyme and cellular androgen metabolism (19). On the basis of these studies and our results, 5RI may have important roles in androgen physiology of normal virilized males.

Despite our clear demonstration of considerable 5RI transcription in GSFs, the exact function of this

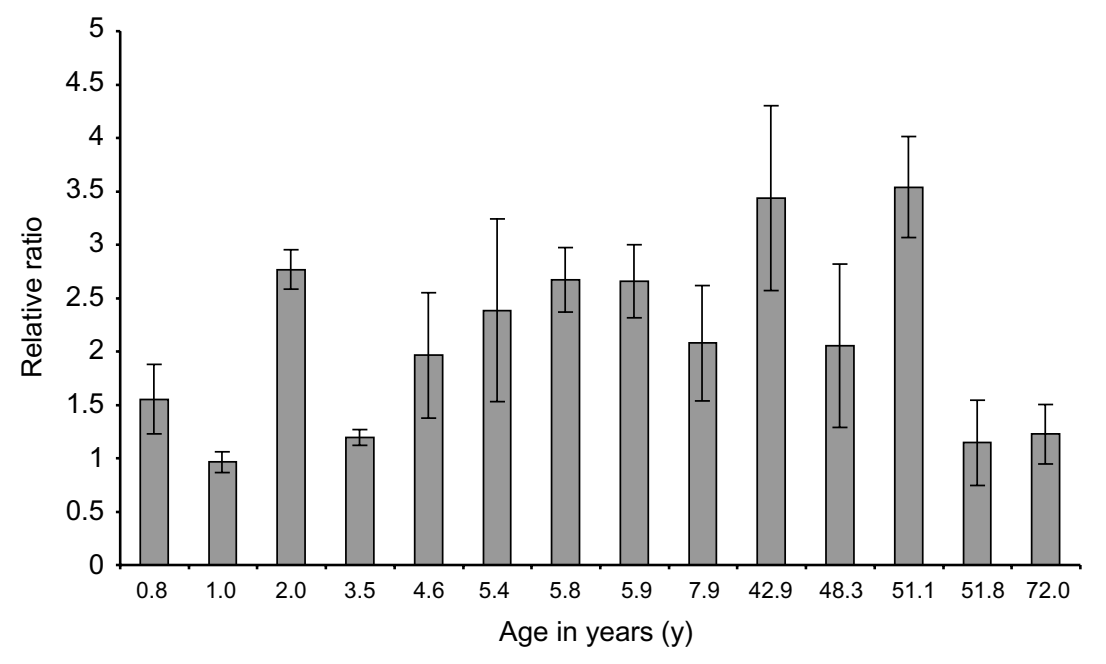

Figure 1 The diagram shows the transcription pattern of $5 \mathrm{Rl}$ in human genital skin fibroblasts (GSFs) of various age groups. The results are described as a relative ratio of the target $5 \mathrm{RI}$ and the housekeeping gene PBGD. To determine the ratio, concentrations of both PCR products were measured. Then the concentration level of $5 \mathrm{RI}$ was divided by concentration level of PBGD using a special quantification software. As each sample was amplified three times, the standard deviation of these investigations is also shown in the diagram. It shows the transcription of $5 \mathrm{RI}$ in all investigated age-groups. We found no specific influence by age, but a high variability in the transcription level of different individuals. 


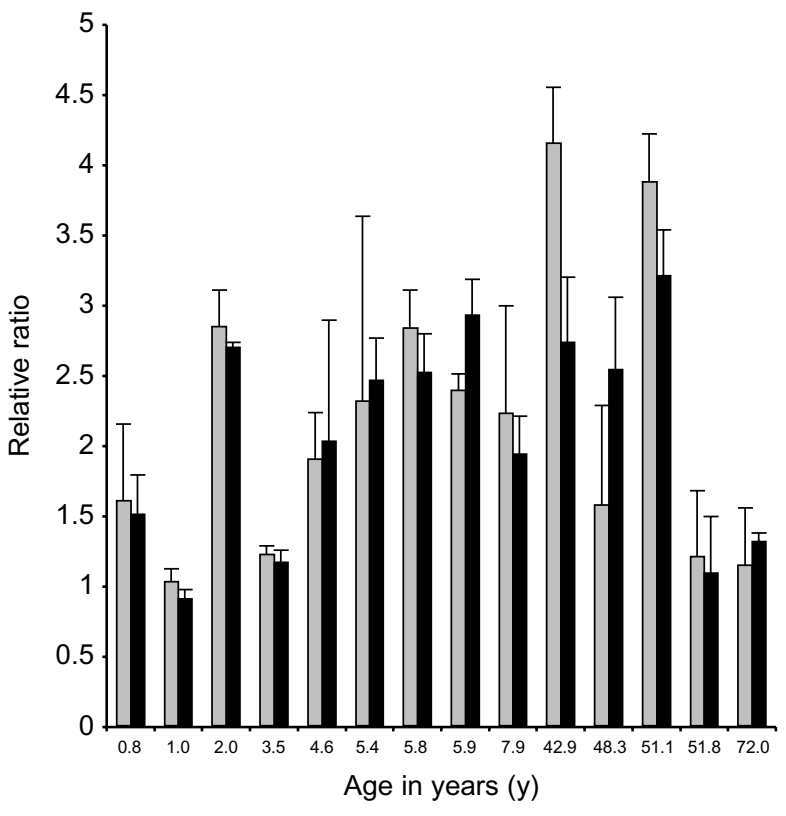

Figure 2 This figure shows the influence of testosterone $(T)$ on the transcription level of $5 \mathrm{RI}$ in human genital skin fibroblast (GSF) cultures. The gray bars demonstrate the relative ratio of cell cultures that were incubated with $100 \mathrm{nM} \mathrm{T}$ for 48 hours, and the black bars depict the ratio of cultures incubated with androgen-free medium. Most samples incubated with or without $T$ reveal similar mRNA concentration. Therefore, there is probably no long-term influence by $T$ on the transcription rate of $5 \mathrm{RI}$. We used the same method for measurement of the relative ratio as described in the legend of Figure 1.

enzyme in androgen metabolism of these cells remains speculative. Both enzymes are expressed in GSFs, but exhibit their acitivity at different $\mathrm{pH}$ values (5). There is some further evidence from transcription studies that in normally virilized human males DHT-synthesis in GSFs could be controlled by both isoenzymes. Hellwinkel et al. (12) investigated the transcription pattern of 5RII in human GSFs of different age groups. As DHT is crucial for the most androgen-dependent processes (23), and based on the assumption that 5RII is the important isoenzyme which produces DHT from $\mathrm{T}$ in GSF, it should be expected that it is transcribed at constant levels despite increasing age. Unexpectedly, Hellwinkel et al. reported a clear decrease of the mRNAexpression of isoenzyme type 2 in adult males below measurable values (12). This is in accordance with earlier studies demonstrating a decrease of enzyme activity with age in patients with virilization disorders and normal controls (24).

In contrast to the type 2 isoenzyme, our present results demonstrate that transcription of type 1 isoenzyme is not influenced by age. Rather, it is transcribed at constant rates at all investigated ages. Therefore, it is likely that the role for type 2 isoenzyme is mainly restricted to virilization of the external genitalia in the embryo (2). In contrast, the type 1 isoenzyme may take over DHT production after puberty and thus contribute to a continuous synthesis of DHT after birth and in later life. The age-independent expression level of the androgen receptor in GSF (12) could indicate a low but continous demand of androgens in these cells provided via 5RI actions with increasing age.

We found up to 4.5-fold differences in 5RI transcription levels between individual cell cultures. Based on well-standardized methods of our present study, we believe that this reflects true inter-individual variabilities of 5RI transcription levels, as is also true for the enzyme activity in fibroblasts (24). This is in accordance with other studies, which showed obvious variations in transcript concentrations of normally virilized males for 5RII in the prostate (25) and in GSFs (12). The detected individual differences in transcript concentrations could contribute to the known, inter-individual variability of normal male sex phenotype and also to explaining the lack of a strict genotype-phenotype correlation in individuals with virilization disorders $(1,2)$.

Our observations indicate that neither the substrate T nor the product DHT control 5RI transcription in cultured GSFs (Fig. 2). This observation was independent from the used cell line, the incubation time and androgen concentration. This is supported by previous studies e.g. in human genital skin melanozytes (26), which also point to an androgen-independent transcription of 5RI-transcription. Similar results were found in GSFs for 5RII (12). In contrast to these experimental observations, studies on other tissues showed either a down-regulation of 5RII by T, e.g. in human liver (27), testis of rats (28) and in brains of adult rats (29) or up-regulation by $\mathrm{T}$ and/or DHT in human prostate (22) suggesting that 5RII is androgen-regulated in some tissues.

For 5RI, there is no report to date in which androgen-dependence of its transcription has been experimentally shown. There are several possible interpretations for the absence of testosterone effects on 5RI transcription in our study: first, SRD5A1 may not be an androgen-regulated target gene and, secondly, investigations on cell cultures do not reflect circumstances in vivo. Therefore, it cannot be excluded that GSFs would be responsive to androgen with respect to 5RI transcription in vivo. In this respect, potential influences of androgens on the transcription rate could be mediated by substances in vivo, potentially synthesized in adjacent tissue under androgen influence, acting in a paracrine manner but these would be absent in the investigated cell cultures. This is supported by a previous study from our own group which failed to show a reproducible androgen response program of these cells using microarray analyses covering a genome-wide scale (17).

Some studies show that mRNA concentrations do not generally reflect the concentrations of the translated proteins or the resulting enzymatic activity of 
5RI accurately $(30,31)$ suggesting potential importance of post-transcriptional or post-translational modifications for this isoenzyme. We have not done experimental studies on the 5RI protein level, however, a possible influence by T or DHT on post-transcriptional and/or post-translational level cannot be excluded. Interestingly, some studies demonstrated good correlations between mRNA concentration and activity of the 5RII isoenzyme (32) supporting in general the biological relevance of mRNA-transcription levels which may also hold true for 5RI.

Since we demonstrated that $5 \mathrm{RI}$ is transcribed in all cell cultures from genital tissue of all different postnatal age groups in contrast to 5RII (12), we hypothesize that this isoenzyme is likely to contribute to masculinization in 5RII-deficient males at the time of puberty. This is in contrast to existing hypotheses suggesting that only $\mathrm{T}$ itself in high doses rather than DHT in lower doses will lead to the masculinization during puberty (33) and that 5alpha-reduction would only be mandatory to amplify the signal. In this hypothesis, however, there is no good explanation why virilization does not occur properly in the 5RII-deficient embryo that is under strong influence of high doses of T. One could speculate that mutations in SRD5A2-gene leading to reduction of 5R2 enzymatic activity would only lead to genital undervirilization, because its isoenzyme 5RI is not sufficiently transcribed in the preliminary stage of external male genitalia during embryonic life (34).

\section{Acknowledgements}

This work is part of a doctoral thesis by Susanne Thiele. We thank Christine Marschke and Dagmar Struve for their excellent technical assistance. The study was supported by the Deutsche Forschungsgemeinschaft (HI 497/4-3 and KFO 111).

\section{References}

1 Imperato-McGinley J, Miller M, Wilson JD, Peterson RE, Shackleton C \& Gajdusek DC. A cluster of male pseudohermaphroditism with 5alpha-reductase deficiency in Papua New Guinea. Clinical Endocrinology 199134 293-298.

2 Wilson JD, Griffin JE \& Russell DW. Steroid 5alpha-reductase 2 deficiency. Endocrine Reviews 199314 577-593.

3 Al-Attia HM. Male pseudohermaphroditism due to 5alphareductase-2 deficiency in an arab kindred. Postgraduate Medical Journal $1997 \mathbf{7 3} 802-807$.

4 Mazen I, Gad YZ, Hafez M, Sultan C \& Lumbroso S. Molecular analysis of 5alpha-reductase type 2 gene in eight unrelated egyptian children with suspected 5alpha-reductase deficiency: prevalence of the G34R mutation. Clinical Endocrinology $2003 \mathbf{5 8}$ $627-631$.

5 Jenkins EP, Andersson S, Imperato-McGinley J, Wilson JD \& Russell DW. Genetic and pharmacologic evidence for more than one human steroid 5a-reductase. Journal of Clinical Investigation $199289293-300$.

6 Sinnecker GHG, Hiort O, Dibbelt L, Albers N, Dörr HG, Hau $\beta$ H, Heinrich U, Hemminghaus $M$, Hoepffner $W$, Holder $M$, Schnabel D \& Kruse K. Phenotypic classification of male pseudohermaphroditism due to steroid $5 \alpha$-reductase 2 deficiency. American Journal of Medical Genetics $1996 \mathbf{6 3}$ 223-230.

7 Imperato-McGinley J, Peterson RE, Gautier T \& Sturla E. Androgens and the evolution of male-gender identity among male pseudohermaphrodites with 5alpha-reductase deficiency. New England Journal of Medicine 1979300 1233-1237.

8 Hochberg Z, Chayen R, Reis N, Falik Z, Makler A, Munichor M, Farkas A, Goldfarb H, Ohana N \& Hiort O. Clinical and genetic findings in male and female patients with $5 \alpha$-reductase deficiency. Journal of Clinical Endocrinology and Metabolism $1996 \mathbf{8 1}$ $2821-2827$

9 Hiort O, Willenbring H, Albers N, Hecker W, Engert J, Dibbelt G \& Sinnecker GHG. Molecular genetic analysis and human chorionic gonadotropin stimulation tests in the diagnosis of prepubertal patients with partial 5 alpha-reductase deficiency. European Journal of Pediatrics 1996155 445-451.

10 Price P, Wass JA, Griffin JE, Leshin M, Savage MO, Large DM, Bu'Lock DE, Anderson DC, Wilson JD \& Besser GM. High dose androgen therapy in male pseudohermaphroditism due to 5alpha-reductase deficiency and disorders of the androgen receptor. Journal of Clinical Investigation 1984 74 1496-1508.

11 Ginzinger DG. Gene quantification using real-time quantitative PCR: An emerging technology hits the mainstream. Experimental Hematology $200230503-512$.

12 Hellwinkel OJ, Muller A, Struve D \& Hiort O. Influence of androgens and age on androgen receptor and 5alpha-reductase II transcription. European Journal of Endocrinology 2000143 217-225.

13 Nirde P, Georget V, Terouanne B, Galifer RB, Belon C \& Sultan C. Quantification of androgen receptor messenger RNA from genital skin fibroblasts by reverse transcription-competitive polymerase chain reaction. Journal of Steroid Biochemistry Molecular Biology $19986635-43$.

14 Pelletier G, Luu-The V, Huang XF, Lapointe H \& Labrie F. Localisation by in situ hybridisation of steroid 5alpha-reductase-isoenzyme gene expression in the human prostata and preputial skin. Journal of Urology 1998160 577-582.

15 Boehmer ALM, Brinkmann AO, Nijman RM, VerleunMooijman MCT, de Ruiter PD, Niermeijer MF \& Drop LS. Phenotypic variation in a family with partial Androgen Insensitivity Syndrome explained by differences in 5alpha dihydrotestosterone availability. Journal of Clinical Endocrinology and Metaboblism 2002 $861240-1246$.

16 Avila DM, Wilson CM, Nandi N, Griffin JI \& McPhaul MJ. Immunoreactive AR and genetic alterations in subjects with androgen resistance and undetectable AR levels in genital skin fibroblasts ligand-binding assays. Journal of Clinical Endocrinology and Metaboblism $200287182-188$.

17 Holterhus PM, Hiort O, Demeter J, Brown PO \& Brooks JD. Differential gene-expression patterns in genital fibroblasts of normal males and 46, XY females with androgen insensitivity syndrome: evidence for early programming involving the androgen receptor. Genome Biology 20034 R37.

18 Mahony MC, Swanlund DJ, Billeter M, Roberts KP \& Pryor JL. Regional Distribution of 5alpha-reductase type 1 and type 2 mRNA along the human epididymidis. Fertility and Sterility $1998691116-1121$.

19 Aumüller G, Eicheler W, Renneberg H, Adermann K, Vilja P \& Forssmann WG. Immuncytochemical evidence for differential subcellular localisation of 5alpha-reductase isoenzymes in human tissue. Acta anatomica 1996156 241-252.

20 Habib FK, Ross M, Bayne CW, Grigor K, Buck AC, Bollina P \& Chapman K. The localisation and expression of 5alpha-reductase types 1 and 2 mRNAs in human hyperplastic prostate and in the prostate primary cultures. Journal of Endocrinology 1998156 509-517.

21 Span PN, Benraad TJ, Sweep CGJ \& Smals AGH. Kinetic analysis of steroid 5alpha-reductase activity at neutral $\mathrm{pH}$ in benign prostatic hyperplastic tissue: Evidence for type 1 isozyme activity in the 
human prostate. Journal of Steroid Biochemistry and Molecular Biology 199657 103-108.

22 Bonkhoff H, Stein U, Aumüller G \& Remberger K. Differential expression of 5alpha-reductase isoenzymes in the human prostate and prostatic carcinomas. Prostate 199629 261-267.

23 Griffin JE \& Wilson JD. Disorders of the testis. In Harrison's Principles of Internal Medicine, edn 15, ch 15, pp 2143-2154. Eds E Braunwald, AS Fauci, DL Kasper, SL Hauser, DL Longo \& JL Jameson. New York: The McGraw-Hill Companies, 2001.

24 Moore RJ, Griffin JE \& Wilson JD. Diminished $5 \alpha$-reductase activity in extracts of fibroblasts cultured from patients with familial incomplete male pseudohermaphroditism, type 2. Journal of Biological Chemistry $1975 \mathbf{2 5 0} 7168-7172$.

25 George FW, Russell DW \& Wilson JD. Feed-forward control of prostate growth: Dihydrotestosterone induces expression of its own biosyntetic enzyme, steroid 5alpha-reductase. PNAS $1991 \mathbf{8 8}$ 8044-8047.

26 Tadokoro T, Itami S, Hosokawa K, Terashi H \& Takayasu S. Human genital melanocytes as androgen target cells. Journal of Investigative Dermatology 1997109 513-517.

27 El-Awady MK, El-Garf W \& El-Houssieny L. Steroid 5alphaReductase Type 1 is differentially regulated by androgens and glucocorticoids in the rat liver. Endocrine Journal 200451 37-46.

28 Lopez-Solache I, Luu-The V, Seralini GE \& Labrie F. Heterogenity of rat type $15 \alpha$-reductase cDNA: cloning, expression and regulation by pituitary implants and dihydrotestosterone. Biochemica et Biophysica Acta 19961305 139-144.
29 Torres JM \& Ortega E. Differential regulation of steroid 5alphareductase isozymes expression by androgens in the adult rat brain. FASEB Journal $2003171428-1433$.

30 Normington K \& Russell DW. Tissue distribution and kinetic characteristics of rat steroid 5alpha-reductase isozymes: evidence for distinct physiological functions. Journal of Biological Chemistry $19922519548-19550$.

31 Cilotti A, Danza G \& Serio M. Clinical application of 5alpha reductase inhibitors. Journal of Endocrinological Investigations 200124 199-203.

32 Söderström TG, Bjelfman C, Brekkan E, Ask B, Egevad L, Norlen BJ \& Rane A. Messenger ribonucleic acid levels of steroid 5alphareductase 2 in human prostate predict the enzyme activity. Journal of Clinical Endocrinology and Metaboblism 200186 855-858.

33 Grino PB, Griffin JE \& Wilson JD. Testosterone at high concentrations interacts with the human androgen receptor similarly to dihydrotestosterone. Endocrinology 1990126 1165-1172.

34 Thigpen AE, Silver RI, Guileyardo JM, Casey ML, McConnell JD \& Russell DW. Tissue distribution and ontogeny of steroid 5alphareductase isozyme expression. Journal of Clinical Investigation 199392 903-910.

Received 11 December 2004

Accepted 17 March 2005 